\title{
TRAJECTORY-BASED SEGMENTATION OF LOYALTY PROGRAM-TYPE DATA
}

Arthur W. Allaway, University of Alabama, USA

Giles D'Souza, University of Alabama, USA

David Berkowitz, University of Alabama-Huntsville, USA

William Magnus Northington, University of Alabama, USA

\begin{abstract}
The emergence of multiple marketing data sets available to marketers has created a need for the best way to analyze and interpret purchasing behaviors among varying segments of customers. In this paper, the loyalty card program of a U.S. mass merchandise retailer is segmented using a trajectory modeling approach. The trajectory modeling technique reveals seven distinct segments of customers within this loyalty card program that we named: (1) premiere, (2) early excitement but faded, (3) late bloomer, (4) moderate but steady, (5) disillusioned, (6) once-a-month visitors, and (7) moderate start but faded. These results provide evidence of the need to customize CRM strategies for multiple customer trajectory segments in order to maximize loyalty and profitability. Furthermore, this paper provides a unique methodological tool to identify and analyze unique customer segments based on their behaviors over time.
\end{abstract}

References available upon request 